\title{
CONSTRUÇÃO DO MUNICÍPIO DE LONDRINA-PR: AÇÕES DE EDUCAÇÃO E DE CULTURA (1934-1960)
}

\author{
CONSTRUCTION OF THE MUNICIPALITY OF LONDRINA-PR: ACTIONS OF \\ EDUCATION AND CULTURE (1934-1960)
}

\author{
Tony Honorato ${ }^{1}$ \\ Bruna Ester Gomes Yamashita²
}

\begin{abstract}
RESUMO: O texto é sobre ações de educação e de cultura presentes no processo de construção do município de Londrina, localizado no Estado do Paraná, Brasil. Em 1934, Londrina se emancipa politicamente enquanto município, e passa a empreender cada vez mais esforços na estruturação da localidade atingindo por volta de 1960 a existência de significativos equipamentos culturais e educacionais. O objetivo do artigo é apresentar ações dos poderes legislativo e executivo em prol da educação e da cultura no movimento de construção do município de Londrina-PR (1934-1960). As fontes históricas centrais selecionadas são os relatórios da Prefeitura e as atas da Câmara Municipal de Londrina, elas foram analisadas considerando aportes de teórico-metodológicos de autores de história da educação e de história local. Como resultado, as ações culturais e educacionais se entrecruzaram e se validaram no plano regulamentador do município de Londrina, marcando a criação de escolas, bibliotecas, teatros para a formação sociocultural dos indivíduos.
\end{abstract}

Palavras-chave: Ação municipal. Poder. Educação. Cultura. Cidade.

ABSTRACT: The text is about educational and culture actions present in the construction process of the municipality of Londrina, located in the State of Paraná, Brazil. In 1934, Londrina emancipated itself politically as a municipality, and it began to undertake more and more efforts in the structuring of the locality reaching around 1960 the existence of significant cultural and educational equipment. The purpose of the article is to present actions of the legislative and executive powers in favor of education and culture in the construction movement of the municipality of Londrina-PR (1934-1960). The central historical sources selected are the reports of the Londrina City Hall and the minutes of the chamber of councilors, they were analyzed considering contributions of theoreticalmethodological authors of history of education and local history. As a result, the cultural and educational actions were intertwined and validated in the regulatory plan of the municipality of Londrina, marking the creation of schools, libraries, theaters for the sociocultural formation of the individuals.

Keywords: Municipal action. Power. Education. Culture. City.

1 Doutor em Educação pela Universidade Estadual Paulista (2011). Atualmente é Professor Associado na Universidade Estadual de Londrina/UEL, Departamento de Educação e Programa de PósGraduação em Educação. tony@uel.br

2 Graduada em Pedagogia, Mestre e Doutoranda em Educação pela Universidade Estadual de Londrina. Professora da Secretaria Municipal de Educação de Londrina. bruna.ester.yamashita@uel.br 


\section{Introdução}

O objetivo consiste em apresentar ações dos poderes legislativo e executivo em prol da educação e da cultura no movimento de construção de um município: Londrina-PR (1934-1960). Trata-se de compreender experiências que possibilitaram aos seus sujeitos figurações diversas no exercício da capacidade humana de se educar num processo de estruturação e ordenamento local.

Londrina é um município localizado na região norte do Estado do Paraná, tem a sua história ligada ao crescimento econômico e populacional relacionado à produção da cultura agrícola, especialmente a do café, e com a chegada dos colonos necessidades educacionais e socioculturais foram ampliadas. Em um cenário de estruturação, segundo Boni (2004), o seu povoamento crescente foi potencializado em 1928 com a chegada de poloneses, ucranianos, tchecos, russos, alemães, japoneses, seguidos de outras dezenas de imigrantes e migrantes. Londrina passou a ser tecnicamente organizada com as ações da Companhia de Terras Norte do Paraná (CTNP) a partir de 1929, que então delimitou e comercializou os lotes dando-lhe um formato urbano (ARIAS NETO, 2008). Município foi instaurado oficialmente em 1934, em 1936 inicia-se a trajetória do poder legislativo londrinense (CESÁRIO; ALMEIDA, 1996).

Considerando o viés regulamentador dos municípios (ADÃO; MAGALHÃES, 2011; MAGALHÃES, 2008), o desafio da pesquisa foi trazer ao debate ações da municipalidade que dizem respeito à educação e à cultura em um território onde as atividades legislativa e executiva aconteciam no contexto das primeiras décadas de construção do próprio município. As ações foram analisadas como políticas locais em interdependências com as políticas estaduais e nacionais. Segundo Cury (2002), o ordenamento regula as relações básicas implicadas na existência social, sejam familiares, econômicas e/ou políticas.

Para realização da pesquisa tomou-se como fonte histórica, principalmente, os relatórios e as atas dos poderes legislativo e executivo do município de Londrina $(1934-1960)^{3}$, sob à luz de autores como Faria Filho e Veiga (1997), Faria Filho

\footnotetext{
${ }^{3}$ Os documentos foram identificados nos arquivos da Prefeitura e da Câmara Municipal de Londrina, estão encadernados no formato de livro de capa dura e dispostos em estantes. Estão em bom estado de conservação, contudo poucos apresentam paginação. Assim para a citação dos documentos que
} 
(1998), Adão e Magalhães (2011), Gonçalves Neto e Carvalho (2015), bem como autores que tomam, cada um ao seu modo, a história local de Londrina como objeto (ARIAS NETO, 2008; BONI, 2004; CAPELO, 2013; CESÁRIO; ALMEIDA, 1996; COUTINHO, 1959). A periodização histórica diz respeito ao ano de 1934 porque foi quando Londrina se emancipou como município e 1960 remete a virada de uma década quando a localidade já se encontrava com significativos equipamentos educacionais e culturais na cena urbana (cinemas, biblioteca, parque infantil, teatro, estádio de futebol, DEPAS - Departamento de Educação e Assistência Social, entre outros).

O estudo revela que relações entre poderes legislativo/executivo, educação e cultura se validando no plano de regulação dos espaços em constante transformação de um município, seja pelas necessidades emergentes da população em setores como o de saúde, escola, saneamento, trabalho, como também nas possibilidades de lazer e de acesso à cultura. Este movimento de edificação do território municipal se dá pela mobilização dos sujeitos políticos, administrativos e civis que exercem papeis numa organização comum e se educam por todo um território, seja pelo ambiente formal da escola como também pelas ações culturais ocupantes de lugares educativos.

\section{Londrina: ações da municipalidade}

O propósito de pesquisar as ações dos sujeitos públicos na construção do município de Londrina implicou olhar para a legislação e localizar as ações por eles efetivadas em prol da educação e da cultura. Aqui, considera-se a lei como uma prática ordenadora das relações sociais. Faria Filho (1998) destaca o caráter histórico e político da legislação, como também o seu potencial de ação sobre os sujeitos responsáveis por esta intervenção social em escala local, regional e nacional. Assim, no caso de Londrina (1934-1960), a mobilização dos sujeitos se dá dentro das possibilidades autorizadas para agir diante da centralidade do governo federal. Desta maneira, a educação e a cultura foram sendo configuradas no território londrinense resultando em muitas práticas dos sujeitos locais que

não constam paginação será utilizado, seguindo a ABNT, a sigla "n.p" (não paginado), bem como foi mantida na transcrição a ortografia de época. 
foram educados, seja pelo ambiente formal da escola ou pelo movimento cultural do município.

Entende-se Londrina enquanto município regulamentador, considerando todo seu território urbano e rural.

Para uma teoria de conjunto é assim necessário equacionar o município como centro-local educativo e como instituinte. O local educativo é portador de individualidade e ideação autárcitas, enquanto parte de um sistema e segmento da estrutura orgânica e administrativa mais ampla, regional, nacional ou mesmo transnacional (ADÃO; MAGALHÃES, 2011, p.18).

Londrina enquanto território municipal em organização, nas suas primeiras décadas de existência, contabilizava uma população rural superior à urbana, condição que se estendeu até poucos anos subsequentes à década de 1950 (LONDRINA, 1954). Nesse contexto, o ambiente urbano e o rural e suas representatividades estabelecem relação de interdependência na pauta educativa, cerceando condutas e modos de vida.

O modo de vida urbano criava cada vez mais a imagem de progresso e civilidade, ao mesmo tempo o campo se fortalecia e tornava foco para se dar garantias para o equilíbrio da ordem por todo município. Segundo Capelo (2013, p. 88), "O entrecruzamento entre rural e o urbano pressupõe a ocorrência de um processo desagregador, que é simultaneamente constituidor de um outro universo sociocultural".

Em um município novo, os sujeitos eram (i)migrantes repletos de planos para agir no processo de ocupação do lugar. Logo a promoção de normas, condutas e regulamentações agregava sentido de responsabilidade e participação no processo da municipalização. O movimento no território efervescia na construção de um modo de vida do londrinense. A relação dos poderes administrativos (executivo e legislativo), para com os sujeitos pertencentes à população, atendia aos poucos os desejos de melhorias, mas ao mesmo tempo tais desejos eram direitos ainda não alcançados ou garantidos.

A partir de suas trajetórias, das novas experiências e práticas sociais é que as identidades de origem serão reconstruídas, incorporando o imaginário da cidade criado pela CTNP e pelos primeiros que aí chegaram. Com o desenvolvimento de Londrina, uma nova heterogeneidade se soma à anterior, a organização em camadas 
sociais acompanhadas da construção de vários espaços menores dentro da cidade: o centro, as vilas, os patrimônios e, mais tarde, os bairros, os jardins, os conjuntos habitacionais. (CESÁRIO; ALMEIDA, 1996, p. 63)

No início da municipalização, o poder executivo deliberava através de ações independentes da existência de uma câmara legislativa, porém em concordância com o governo federal e a Constituição Federal de 1934. Mesmo que a administração política passasse a ser formalizada no âmbito local em 1934, os habitantes de Londrina já se organizavam antes enquanto comunidade, mesmo que pequena, mas possuidora de organização própria, como também de escola. 0 Sr. Jorge Strass, de família de imigrantes alemães na década de 1920, relata: "A preocupação dos alemães era a de construir uma escola, pois eles vieram de uma região onde era obrigatório estudar [...]" (LONDRINA, 1993, p. 23).

Com a primeira Câmara de Vereadores, eleita em setembro de 1935, denominada Câmara Pioneira, o legislativo formalizado iniciou atuação em 1936. No período de um ano, a primeira legislatura aprovou 38 leis para a organização inicial do município. De modo geral, havia uma preocupação com a organização urbana e rural no que diz respeito à infraestrutura, higiene, segurança e saúde pública. Das 38 leis aprovadas, 07 se referiam à educação municipal (LONDRINA, 1936- 1937).

Uma atuação pública municipal implica, conforme Magalhães (2008), na representatividade e validade das ações. No final da década de 1930, o projeto educativo londrinense local e regional se insere no ideário de um projeto educativo nacional e o município age enquanto organizador. Seja pelo Convênio Nacional do Ensino Primário de 1930 ou pela Constituição de 1934 e a de 1937, o território municipal fora considerado um agente de validação das ações para a educação dos brasileiros e ao mesmo tempo o município de Londrina, por meio da pauta legislativa, pede urgências de infraestrutura, transporte e saúde pública.

No período de 1937 a 1947, em que as câmaras legislativas foram dissolvidas devido ao Estado Novo, é possível perceber, pelos atos do executivo, um constante movimento regulamentador exercido pelo poder municipal. Observa-se um projeto de nação refletido para este território através da interventoria estadual. As regulamentações eram para a ocupação do espaço físico, social e econômico e que vinham dando ao município traços de civilidade, 
os quais dariam aos sujeitos condições de uma educação não escolar promovida por uma cultura urbana, pela sociabilidade. A competência dessas ações fundamentava-se na legislação:

Art. 12. Compete ao Prefeito:

I - Expedir decretos-leis nas matérias da competência do Município; II -expedir decretos, regulamentos, posturas, instruções e demais atos necessários ao cumprimento das leis e à administração do Município; [...]. IV - Nomear, aposentar, pôr em disponibilidade, demitir e licenciar os funcionários municipais, e impor-lhes penas disciplinares, respeitando 0 disposto na Constituição e nas leis (BRASIL, 1939, n.p).

Nos dez primeiros anos do município de Londrina (1934-1944), foram executados um total de 586 decretos, sendo 210 relacionados direta ou indiretamente à escola, entre eles estão: atos de criação de escolas, contratação e nomeações de professores, subvenção para instituições, financiamento, transferências e outras adequações necessárias para 0 atendimento e funcionamento escolar.

Em 1947, com o fim do período de intervenção estadual, a nova administração pública traz à Londrina mais uma vez a representatividade legislativa já em um município com cerca de 67 mil habitantes (LONDRINA, 1954). Nessa administração, o prefeito eleito Hugo Cabral instalou um considerável número de escolas junto à denominada primeira legislatura no município de Londrina (1947-1951), como pode ser observado:

Em 1947, existiam 28 escolas primárias municipais, mas, praticamente, funcionando só havia 25, com 38 professores e 1402 alunos matriculados; atualmente, excluindo 2 escolas que passaram para Cambé, em consequência do desmembramento do município, esses números se elevam a 33 escolas com 50 professores (LONDRINA, 1948, v. 1, p. 6).

Com o poder legislativo eleito, a atuação para a positivação dos direitos relacionados às necessidades urbanas, bem como aos da escola, configura mais uma vez a validação transformativa do território municipal. Localizam-se aí as representações do poder público nas tramas do município, e por elas o discurso se faz em concordância ao Plano de Educação Nacional, como pode-se ler no parecer da Comissão de Educação ao PL no 3 de 1948: 


\begin{abstract}
A finalidade precípua do projeto em causa é a criação de uma escola primária, que deverá situar-se na Vila Brasil, florescente setor população de suburbana desta cidade. A creação da escola é questão de quanto mais, pois, como sabemos a educação é o problema máximo de nossa nacionalidade. Logo assim, toda vez que se reclama do poder público a instalação de uma nova escola, notadamente do poder público a instalação de uma nova escola, notadamente do curso primário, consequência do surgimento de novos núcleos populacionais, não se deve dificultar a sua efetivação. Pelo contrário pensamos nós, deve ser o poder público acudir pressuroso pedido dessa natureza agir de modo diverso seria verdadeiramente impatriótico importando mesmo índice visto a grande é nobilitante campanha em que por todos os Recantos do país governa o povo empenham-se com o ânimo e resolução elogiáveis visando combater o analfabetismo (LONDRINA, 1948, v 1, p. 06).
\end{abstract}

A conjuntura na qual se inclui o movimento educador pela ação municipal, naquele tempo histórico, permite aos municípios agirem e governarem dentro de regulações maiores com possibilidades oriundas de uma centralidade de poder. As regulamentações a partir de 1948, seguiam de acordo com a Lei no 64 de 21 de fevereiro de 1948, a Lei Orgânica dos Municípios (BRASIL, 1948). Observa-se que das 644 leis sancionadas entre 1934 e 1960 pelo poder legislativo de Londrina, 161 referem-se direta ou indiretamente à educação escolar e cultural. Ressalta-se que, cultura, inclui-se nas leis selecionadas pois em grande parte dos tópicos pautados, discutidos e deliberados, Educação e Cultura são apresentadas juntas e assim ambas são consideradas significativas para compreender o perfil do município.

O movimento legal em favor da escola acontecia no município, já os debates pelas causas escolares e pela criança na Câmara Municipal de Londrina (CML) não se demonstravam tão forte. Pôde-se até mesmo observar nas atas que o legislativo pouco se pronunciou sobre a pauta da escolarização no território. O fato é que a escolarização local acontecia em muito por causa das respostas municipais às leis estaduais e nacionais.

A conquista dos direitos dos cidadãos de Londrina nesse período, demonstra estabelecer-se por relações sociais e políticas, revelando novas possibilidades de relações de interdependência entre os grupos numa relação de poder muito centralizadora. A população e a municipalidade constituem uma configuração promotora de estruturas sociais que funcionam, geram laços, se controlam e se dependem para funcionar. Os indivíduos nesse contexto passam a abrigar um 
autocontrole através do controle social interiorizado, que então se dá pela regulamentação do município, do meio social e da educação que extrapola também o que propõe o espaço escolar.

\section{2- Além dos muros da escola, a educação no projeto urbano}

O município educava, e a documentação pesquisada evidencia a concretização de atos que atendiam a educação escolar, bem como a orientação de condutas e comportamentos para além da escola. O contexto educador no desenvolver inicial de Londrina, não se dava somente na escola, que ainda era tímida, e sim também nos modos e condicionamentos dos comportamentos no cenário urbano. As configurações da educação escolar, ou da educação pelo espaço em ocupação, eram apresentadas e colocadas em pauta nas discussões da Câmara Municipal de Londrina (CML). Pois, como Forquim (1993, p. 125) colabora a compreender, "A educação veicula e produz a cultura, ou seja, as práticas culturais só são possíveis devido à possibilidade humana de se educar".

No município de Londrina, faziam-se homens e mulheres. Novos londrinenses que eram envolvidos nos planos e orientações que davam impulso ao espaço educador. Pertencer ao espaço e fazê-lo era preservá-lo e também tirar dele seu sustento e modo de vida. Nesse contexto muito se influenciava pela 'bagagem' que cada um trazia de suas culturas e costumes carregados por suas trajetórias. Sujeito influenciando sujeito e esse movimento certamente originava nos indivíduos um novo olhar, um desequilíbrio e posturas se faziam pelo convívio em um território local. A capacidade humana de se educar acontecia no processo de municipalização.

Conforme Boni (2004), em Fincando estacas: a história de Londrina (década de 30) em textos e imagens, os habitantes do novo município logo se viram inquietos naquele núcleo em que atividades sociais, distrações e cenas de convívio coordenadas, logo se tornam necessárias para que as relações fluíssem além do estrutural. Igrejas, centros sociais, festividades e lugares públicos de lazer seriam garantias de bem-estar aos moradores.

Identificam-se entre os primeiros decretos municipais atos que demonstram

História \& Ensino, Londrina, v. 27, n. 1, p. 374-399, jan./jun. 2021 
notas de ordem e progresso. Condições de cidadania, regulação e civilização constituem nas pessoas envolvidas posturas e condicionamentos que se tornarão parte de suas rotinas, limitadoras de seus hábitos e muitas vezes imperceptivelmente projetadas em um território enquanto experiência educativa com o papel de civilizar hábitos dos moradores. Para Elias (1994), em O processo civilizador, fatores pelos quais as influências sofridas pelos homens ao longo dos tempos na configuração da civilização permitem com que os próprios homens sejam modelados pelos comportamentos e imposições de outros. Em uma de suas definições, o autor apresenta que a "civilização descreve um processo ou, pelo menos seu resultado. Diz respeito a algo que está em movimento constante, movendo-se incessantemente para a frente" (ELIAS, 1994, p. 24).

Uma ocupação territorial no norte do Paraná, com fins comerciais não compatíveis a uma proposta de povoamento que fosse acolhedora ao povo, gerou carências oriundas da escassez de estrutura voltada ao bem-estar coletivo. A chegada dos (i)migrantes em Londrina trazia a necessidade de condições de dignidade e de condicionamento de suas ações diversas no espaço municipal para exercer a cidadania, e, além da escola, outros lugares são também campo desta atuação. Pois, como colocam Faria Filho e Veiga (1997, p. 204), "a produção de um novo sujeito urbano é parte das inúmeras utopias da modernidade onde se elabora entre outras, a dimensão educativa da cidade e a perspectiva urbanizadora da escola".

O cuidado com os interesses pessoais locais passou a ser exercido com maior regularidade, a partir da representação política da formação do município que se passou a pensar nas condições de desenvolvimento voltadas ao indivíduo na localidade, com medidas de organização necessárias, bem como de certas condições para a realização de atividades profissionais, de convivência, como também de instrução para atuar no espaço municipal.

O caso a seguir ilustra como o município direcionou e exigiu condições e pré-requisitos aos cidadãos. Lê-se na ata da sétima reunião da primeira sessão ordinária da Câmara Pioneira, em 4 de março de 1936, que estipula desde então o registro obrigatório de específicos profissionais.

Fica instituído no município o registro obrigatório de engenheiros, construtores e architectos, agrimesores e construtores de obras. 
Art. $2^{\circ}$. Nenhum serviço municipal será confiado a profissional que não tenha obtido o respectivo registro. Art. $3^{\circ}$ Para o registro terá o profissional em engenharia de qualquer ramo ou agrimensor ou construtor de obras, de apresentar um requerimento á Prefeitura, [...] com os necessários documentos de habilitação e de estar quites com a fazenda do Estado e a do município [...] Art. $6^{\circ}$ As construções no perímetro urbano e suburbano é, bem assim nas sedes dos distritos de paz ou cidades consideradas em formação, somente poderão ser executadas por construtor de obras devidamente registrado [...] (LONDRINA, 1936, v. 1, p. 10)

Um ato de regularização promove múltiplas implicações aos sujeitos envolvidos na atividade profissional. O cadastro junto à Prefeitura, os registros, a situação legal com a Fazenda do Estado e a do Município, incutiam nos sujeitos comportamentos e relações com o território administrativo, direcionariam ações, tensionariam condutas e reordenariam relações de trabalho expectativando aprimoramento das ações profissionais formadoras e educadoras dos indivíduos. Para executar as exigências acima citadas, entre outras que estariam por vir, os indivíduos necessitariam de no mínimo alguma instrução para ter condições de trabalho, faz então o município uma escola para seus indivíduos. Por este aspecto, a construção de Londrina foi também a construção de novas formas de trabalho, novas formas de relações, de necessidades e de educação para as relações sociais, culturais e profissionais em ascensão.

Só a visão de uma grande cidade onde sem nada querer aprender, alguém se instrui a todo instante, onde para se conhecer mil coisas novas, basta caminhar na rua de olhos bem abertos, essa visão, essa cidade, sabei, é uma escola (FARIA FILHO; VEIGA, 1997, p. 203).

Havia um cenário municipal reorientador às pessoas que nele se encontravam e transitavam. Assim seguem os caminhos de Londrina, uma escola para os indivíduos, colocando-se diante deles pelo processo de urbanização.

Saber das condições para se viver e organizar num território municipal, norteia não somente passos políticos administrativos como também gera planejamentos, criticidade e oportunidade de escolhas, seja para o trabalho, lazer e outras formas culturais potencializadores de condutas e hábitos. Neste sentido, notam-se indivíduos apurando seus comportamentos em específicos lugares numa sociedade local em organização. Através da administração política discute, planeja, 
ordena e executa ações para alocar pessoas nos seus espaços e comportamentos desejados.

Sobre a regulamentação de Londrina durante o Estado Novo (1937-1945), observa-se constituição da regulação do comportamento dos indivíduos no município. Fiscalizações diversas sendo decretadas e estabelecidas. As medidas eram sanitárias, de infraestrutura, de conduta, de segurança. Criam-se também para este cidadão algumas condições de acesso à cultura e dá possibilidades de contato com um mundo civilizado, muito familiar às rotinas de muitos (i)migrantes que vieram e ainda não tinham encontrado na localidade possibilidades semelhantes às de suas origens.

Outros incentivos à implementação cultural tomam forma no contexto da regulamentação política. O desenvolvimento traz à política condições de moldar os indivíduos pertencentes ao município de acordo com os interesses de organizar o contexto urbano, suburbano e rural. O contexto da vida social é pensado, seja pelo interesse de culturalizar os indivíduos ou ainda de dar a eles um patamar mais elevado que seja mais próximo do que se vive nos grandes centros e outros lugares de onde vieram seus idealizadores.

As formas educativas enquanto tecidas na cidade, nas experiências urbanas, nos confrontos entre os diferentes sujeitos sociais, na 'politização da rotina' de seus moradores, precipita nas elites a preocupação em assegurar o diferenciado acesso à propriedade ao mesmo tempo que quer incorporar os 'dependentes material e culturalmente' ao seu projeto de cidade e sociedade (FARIA FILHO; VEIGA, 1997, p. 213).

Em consonância à legislação nacional, o município agia para também promover condições para o fomento das atividades assistenciais e culturais. $\mathrm{Na}$ administração do prefeito de Londrina Major Miguel Blasi, artigos do Decreto-Lei no 52 de 19/07/1943 indicam passos que o município deu em relação à educação além escola:

CAPÍTULO I Das formas de subvenção

Art. $1^{\circ} \mathrm{O}$ município prestará sua cooperação financeira às entidades privadas, assistenciais ou culturais, quer mediante a concessão de subvenção fixa anual, para auxiliar a realização de seus objetivos normais, quer de subvenção extraordinária, para ocorrer a serviços de natureza especial ou temporária, também executadas pelas 
mesmas entidades (LONDRINA, 1942-1945, v. 3, n.p).

O poder executivo continuou possibilitando condições para que as subvenções fossem mantidas, as quais eram carregadas de condições e prérequisitos de moral e boa conduta dos responsáveis pela manutenção e direção das instituições subvencionadas. Isso se torna evidente no processo de concessão e pagamento das subvenções.

Em 1945, o município regula espetáculos teatrais (Decreto lei municipal no 52), em 1946 doa um terreno ao Grêmio Litero Recreativo Londrinense (Decreto lei municipal n0137) (LONDRINA, 1942-1945, v.3), pensa um cenário além do administrativo voltado para a estruturação física básica. Identificam-se ações promovendo mais figurações humanas que vão sendo desenhadas pelos lugares ocupados pelas pessoas, nas quais elas vão se relacionando e de certa forma se estruturam socialmente.

As medidas administrativas e os passos políticos foram tomando corpo pelo município. Em 1949, em registro de ata da CML, o Vereador Newton Leopoldo Câmara (PTB- Partido Trabalhista Brasileiro), membro da Comissão de Educação, Recreio e Assistência Social, tem a palavra para declarar que se procurava realizar em Londrina um Congresso Pro Paz e Cultura. Havia ocorrido pelas redondezas do norte do Paraná situações de arbitrariedade policial que levaram à morte, uma mulher e uma criança. Algumas representações na CML buscavam se manifestar em caráter legal e para protestar contra qualquer arbitrariedade policial semelhante. No entanto, a proposição no 17 , que tinha a finalidade de proibir a manifestação dos representantes políticos e que era de origem da representação policial, foi apresentada a fim de coibir o movimento em favor da paz. Aristeu dos Santos Ribas, vereador pelo PSP (Partido Social Progressista), leu a circular da chefia de polícia recomendando às autoridades municipais a proibição do Congresso. Por 6 votos a 5, constou-se a rejeição da proposição no 17 . No dia seguinte uma circular da polícia chega à CML proibindo a realização do Congresso Pro Paz e Cultura (LONDRINA, 1949, v. 2A).

Nessa ocasião há tensão nas relações entre os agentes políticos, civis e militares. Nota-se na experiência da manifestação política e popular, a possibilidade de estabelecimento de novas relações com o município no que diz respeito à conquista do direito de manifestar-se, posicionar-se e exercer a 
cidadania. Contudo, por esta vez, a pauta social foi vencida e negada, afirmando interesses de uma postura rígida, soberana e controladora.

Nos anos da primeira legislatura (1947-1950), após o Estado Novo, na CML prosseguem-se discussões evidenciando problemas emergentes no município, são notórios assuntos de urgência no contexto da época, relacionados à água, telefonia, energia elétrica, canalização pluvial, obras públicas, impostos e taxas, recolhimento de lixo, epidemias na lavoura de café, saúde pública, segurança pública, ordem pública, entre outros. A figuração municipal estava em efervescência de ordenamentos para educar os munícipes em muitos sentidos.

\begin{abstract}
Neste sentido, a urbs instalada, e nela os novos habitantes, distribuindo-se diferentemente, produziram símbolos concretos na nova civitas, buscando nesse esforço homogeneizar as práticas heterogêneas da fixação material e cultural de seus sujeitos. São vários os empreendimentos para constituir os marcos simbólicos que denotassem o progresso das mentes e instituíssem a civilidade (VEIGA, 1994, p. 323)
\end{abstract}

São inúmeras as formas educadoras no contexto municipal e ao mesmo tempo contraditórias. A diferença social e cultural entre os habitantes de Londrina não deixou de existir durante os anos de 1940 e 1950. A cultura cafeeira trouxe riquezas, hábitos e prazeres que não eram comuns à grande parte da população, mas que gerariam influências nos indivíduos. É possível localizar solicitações que expressam prioridades nos debates dos representantes da $\mathrm{CML}$, como é caso de que em 14 de novembro de 1950, o Vereador Josino Alves da Rocha Loures (PRPartido Republicano), membro da Comissão de Educação e como orador na sessão, expressa-se:

[...] lembrou-se de trazer a debate um assunto de importância capital, o problema cultural. Em Londrina temos vários órgãos de imprensa, Rádio Emissora, clubes recreativos e literários e uma revista, como é a 'Pioneira' do Sr. Benedito Barbosa Pupo, que por sua feição material e especialmente por sua parte intelectual, eleva Londrina e se destaca mesmo nos grandes centros intelectuais do país. Prosseguindo o orador fala da necessidade de ser entregue ao público londrinense uma biblioteca que Ihe possa ser útil, por isso que, a existente é desconhecida de grande parte do público. Que é preciso que se dê a Londrina uma biblioteca a altura cultural de nossa cidade (LONDRINA, 1948-1955, v. 3, n.p). 
Mais uma vez os estabelecimentos de acesso à cultura chegam ao município, junto da 'bagagem' daqueles que nela se estabelecem. Em 1951, identificam-se indícios de valorização das relações entre os sujeitos que já faziam parte da formação escolar. Em meio à urbs, a classe estudantil crescia e se instruía. Em exposição ao PL no 07/1951, do Prefeito Hugo Cabral, justificava-se a doação do terreno à Casa do Estudante:

Ninguém ignora já ser a Londrina de nossos dias um grande centro educacional. Eleva-se a uns 6.000 o número de estudantes, que em nosso município, frequentam cursos primários, secundários especializados. O potencial econômico, a posição geográfica e a densidade demográfica, que cada vez mais se acentua, desta região inigualável, em futuro próximo haverão de transformar Londrina no segundo centro universitário do Paraná. Nestas condições, não poderia o Governo Municipal, cuja função essencial deve ser a de zelar pelo bem-estar presente e futuro do povo, deixar de construir através dos meios e das medidas ao seu alcance, para que, em tempo oportuno, venha nossa cidade a possuir, a exemplo de tantas outras, uma casa destinada a ser o lar dos estudantes e o centro de irradiação cultural das gerações futuras de nossa terra. (LONDRINA, 1950-1951, v. 05, n.p).

A fixação dos novos hábitos sociais e culturais efervescia entre as demandas sociais da localidade. As relações entre os grupos sociais também se constituíam pelo desenvolvimento dos dispositivos legais. Outros atos legais se fizeram para fomentar o desenvolvimento cultural dos sujeitos, medidas a partir da legislação nacional, como é caso do discurso positivo anexo ao PL n 05/1951, assinado pelo Prefeito, destinando um terreno para construção de um teatro e uma biblioteca municipal.

É do conhecimento de todos o extraordinário desenvolvimento econômico desta cidade e desta zona. Não menos conhecido é o fenômeno muito peculiar às regiões novas, como a nossa, cujas populações e encontram, via de regra, inteiramente absorvidas por preocupações de ordem econômica e financeira, que geralmente se verificam de ficar estagnadas são amortecidas por algum tempo as atividades e coisas, ações culturais do povo. Entendemos, entretanto, que este estado de coisas já começa a sofrer grande modificação, pois se observa de uns tempos a esta parte grande curiosidade cultural em nosso corpo principalmente no que concerne à mocidade londrinense. Nestas condições, julgamos oportuno garantir desejar um local onde as futuras administrações possam construir um edifício para nele funcionar um teatro o auditório e a biblioteca pública municipal, que de certo exercerão, futuramente, 
grande influência no desenvolvimento científico, literário e artístico de nossa população (LONDRINA, 1950-1951, v.5, n.p.)

O desenvolvimento econômico de Londrina ocasionou e impulsionou experiências que direcionavam modos de vida. O convite para a experiência urbana carregava projetos para os sujeitos que provocariam mudanças em seus pontos de vista, sonhos, opiniões e hábitos e que poderiam esses projetos ter intenções pedagógicas até mesmo na organização do espaço municipal. Tem-se por exemplo a Lei no 187 de 1953, a qual autoriza o executivo municipal a criar uma autarquia para construção, administração e exploração do estádio municipal, tendo um de seus fins o incentivo à cultura, ao esporte e à arte. O desenvolvimento do local gerava ações para promover não só a infraestrutura organizada, mas também elementos modernizadores variados, dando-os condições de bem-estar, valorização social, de inserção no mercado de trabalho (LONDRINA, 1953, v.9).

Finais da década de 1940 e início de 1950, os debates presentes nas atas da CML baseavam-se no plano urbanístico da cidade devido aos entraves oriundos do aumento populacional e em consonância ao processo de modernização do Estado do Paraná. Eram muitos os problemas apontados pelos agentes da Câmara e que criavam força no espaço local cobrando planos e ações com intenções educadoras que extrapolassem a escola em diferentes direções civilizatórias. Neste sentido, foram propostas leis de autorização de doação e construção de parques infantis em 1953 e 1955, de desconto de 50\% no preço da passagem aos estudantes no transporte urbano em 1954, de subvenções à Sociedade de Cultura Artística de Londrina (SCAL) e ao Grêmio Literário e Recreativo Londrinense. Essas são curtas demonstrações de atos legislativos que possibilitam aos indivíduos condições de lazer, de inserção sociocultural e de mobilidade urbana.

Nos atos legais, nota-se também respondência ao plano nacional de modernização do estado e do país. A lei municipal no 256 (PL no 41/1954) previa parte dos recursos para atender as ações supracitadas, e menciona também que outras garantias concordavam com os artigos 32, 62 e 73 da Constituição Federal (BRASIL, 1946) com o decreto lei federal no 2416 (BRASIL, 1940).

A partir das garantias, tem-se a abertura de possibilidades educadoras que marcariam o setor artístico, cultural e social de Londrina. Encontra-se então o favorecimento de ações em espaços específicos na cidade e sua localização como 
territórios de acesso à outras sensações. Em destaque, a Sociedade de Cultura Artística de Londrina (SCAL) que teve atividades desenvolvidas no ano de 1954 e suas realizações alcançaram parte da população do município, a qual teve contato com cenas culturais que já eram vivenciadas em outras cidades brasileiras.

Anexo à Lei no 290/PL no 30/1955, que orça a receita e fixa a despesa do município de Londrina para o exercício de 1956, a SCAL apresenta um relatório de 6 páginas datilografadas versando sobre as suas atividades de fevereiro de 1954 à fevereiro de 1955. Conforme o relatório, as apresentações artísticas aconteciam no espaço de teatro do Grupo Escolar 'Hugo Simas'. Na primeira temporada artística da SCAL, realizada em 1954, o município contou com a presença de artistas nacionais e estrangeiros reunidos em nove recitais de ballet, canto, conjunto coral, violino, piano e declamação, e finaliza o texto explicitando os esforços da municipalidade:

Assim temos, neste resumo de atividades e de comentários, que Sociedade de Cultura Artística de Londrina 'não tem poupado esforços para dar a Londrina um ambiente de arte a altura do seu progresso' e que seus concertos por ela organizados e patrocinados mereceram por parte dos seus sócios e do público, os mais entusiásticos aplausos (LONDRINA, 1955-1956, v. 14, n.p).

A relação cidade, educação e comportamentos civilizados, evidencia a inserção cultural defendida nos discursos da municipalidade, como também o refinamento de condutas dos indivíduos. A mobilização para esta garantia à sociedade londrinense, ganha espaço e notoriedade em meio a todo movimento urbanizador da localidade. O refinamento das condutas talvez não alcançasse a todas as pessoas do município através da inserção cultural, isso devido às diferenças de grupos sociais e de seus acessos aos espaços públicos.

No conjunto da sociedade, o grupo que era mais favorecido ao contato com os ares de urbes através de apresentações culturais, caminhava em paralelo à outra parte da sociedade que ouvia falar dos eventos, das apresentações e das peças teatrais, mas que ao mesmo tempo, tanto carecia de condições básicas na consolidação dos seus direitos como os de infraestrutura nas vilas e o de ir e vir com segurança. Um distanciamento entre esses grupos sociais acontecia na cena urbana e rural. Uns se percebem mais civilizados por estarem servidos pela cultura e outros menos por não terem nem mesmo o mínimo para sua qualidade de vida. 
Uma expressão disso e no que diz respeito ao direito de circulação e mobilidade que envolve a segurança do povo, destaca-se o projeto para construção de uma passagem em desnível sob os trilhos da Rede Viária Paraná Santa Cataria (RVPSC), que separava um e outro lado da cidade, como consta em ata da CML:

Até o presente momento não foi apresentado à Câmara nenhum plano, projeto ou orçamento da referida obra. Todavia, de modo oficioso, em caráter particular, nos foi apresentado um 'estudo' ou ante-projeto de uma passagem em desnível para veículos e pedestres, sob os mencionados trilhos[...] A solução que se apresenta não é a que melhor atende aos interesses do povo, já porque envolve despesa de milhões de cruzeiros, já porque não atenderá as necessidades da população residente na zona norte da cidade, constituindo assim um desserviço à comunidade. (LONDRINA, 1954, v. 10, n.p).

A construção de um município implica na ocorrência de planos regulamentadores do cenário urbano e das condições de vida dos indivíduos, como destaca Magalhães (2008). Assim, a fisionomia urbana de Londrina e o seu plano de mobilidade limitariam ou encorajariam o indivíduo a ser pertencente à localidade. Tal tensionamento coloca em reflexão princípios de inclusão e exclusão nos modos de vida na cidade.

Em Londrina, os agentes públicos continuaram a defender a promoção da cultura e atividades educacionais no município. Com a frase "estimular por todos os meios as atividades educativas e culturais", relatórios e exposições justificativas vão reforçando a pertinência de educar a partir da cultura:

1956 - A Administração procurou sempre estimular por todos os meios as atividades educativas e culturais do município.

Assim vem contribuindo para a realização de recitais de arte e conferências, bem como enriquecendo as estantes da Biblioteca Pública com inúmeras e valiosas coleções de livros (LONDRINA, 1956 , v. 3, p. 45).

\section{3- Espaço de educação cultural para os indivíduos: a Biblioteca Pública Municipal}

Nos anos de 1930 a 1950, o processo modernizador para a educação do povo, gerou disseminação da necessidade de educação para a nação. Havia crença 
no poder regenerador da educação pela implantação dos sistemas escolares, estendendo a corresponsabilidade de ação aos municípios. Esse movimento potencializou também espaços culturais formativos dos indivíduos. Os espaços culturais na cidade geram também a sociabilidade do indivíduo no meio em que se insere e pelo qual é atendido pelas ações de seus administradores públicos.

Variando com os períodos históricos e com os quadros políticos, a influência municipalista foi acentuada ou mesmo determinante nos planos geográfico, demográfico, cultural, para a evolução sociocultural em geral e, muito particularmente, junto de determinados públicos (ADÃO; MAGALHÃES, 2011, p. 13).

Em resposta às políticas nacionais, a Biblioteca Municipal veio acontecer em Londrina com respaldo do INL (Instituto Nacional do Livro - criado em 1937). Criada por lei em 1940, a Biblioteca Pública de Londrina foi posteriormente inaugurada em ato público em 4 de dezembro de 1951. Foi instalada em edifício da própria municipalidade e funcionava naquele ano em dias úteis das $9 \mathrm{~h}$ às $11 \mathrm{~h} 30$, das $13 \mathrm{~h} 30$ às $17 \mathrm{~h}$ e das $19 \mathrm{~h}$ às $22 \mathrm{~h}$.

Ter uma biblioteca municipal somaria ao contexto da cidade em desenvolvimento e que pudesse cada vez mais alcançar seus cidadãos civilizados. As singularidades do local educativo se expressam aqui também pelo espaço formal de leitura e cultura através da biblioteca como uma forma de evolução pela educação ofertada ao povo. No início do ano de 1951, o Prefeito Hugo Cabral expressa-se em correspondência enviada à CML e anexa ao PL n 5/1951, que posteriormente efetivou-se pela Lei no 109, o teor de sua posição em relação à conquista deste espaço (LONDRINA, 1950-1951, v.5).

A dinamicidade da transformação do município de Londrina pedia medidas legais, planos e projetos, os munícipes por sua vez sentiam a aplicação das ações demandadas pelo governo federal. Segundo Paiva (2008, p. 30), "A extensão da política do livro às bibliotecas públicas visava a criação de um sistema nacional de bibliotecas, para coordenar e promover a modernização dos serviços bibliotecários". Para a autora, primeiramente a função da biblioteca pública era a de guarda da cultura nacional oficial e em segundo plano ter funções educacionais relacionadas também ao lazer e à cultura. 
Reorganizar as estruturas de ensino e de muitos dos mecanismos para fortalecer as aprendizagens e a formação cultural dos indivíduos, eram, pois maneiras de oferecer a eles condições de apropriar-se do que era conveniente aos interesses do governo federal. Mesmo que eleitos por alguém ou por um plano de governo, eram estes mecanismos que davam de certa forma condições aos indivíduos de se educarem em interação com específica cultura, com a modernidade trazida pela leitura e os saberes do mundo letrado.

O espaço de leitura acontecendo em Londrina na década de 1950, marcava efetivação do caráter da política nacional do período. Nos relatórios do executivo local, identifica-se a prestação de contas que registra também o número de participantes da Biblioteca. Uma boa parcela da população usufruía deste espaço e a partir dos documentos históricos consultados não foi possível precisar quem eram esses leitores. Os dados mostram um acervo de 1.963 títulos no ano de 1952 e com um número de consultas de 209. Em 1953, os leitores inscritos eram 875 e o acervo cresceu para cerca de 6.000 títulos, o que evidencia uma crescente considerável nas condições para o espaço de leitura. A biblioteca circulante também estava em funcionamento (LONDRINA, 1952-1954, v. 2).

Em nota no relatório do executivo do ano de 1954, o texto ratifica o intuito das políticas nacionais. Afirma que a administração sempre buscou incentivo e estímulo por todos os meios para as atividades culturais e um dos exemplos destes esforços, apresenta-se pelo texto relacionado diretamente à Biblioteca quando diz que a municipalidade vem "enriquecendo as estantes da Biblioteca Pública com inúmeras e valiosas coleções de livros" (LONDRINA, 1952-1954, v.2). Já no ano de 1958, o acervo era de 7.489 títulos somados às 17 coleções adquiriras neste mesmo ano, científicas, didáticas e literárias. Ainda neste cenário os leitores compreendiam um número de 6.743 inscritos e o fomento à cultura do livro percorria anos seguintes. (LONDRINA, 1958, v.5)

A fim de que a cultura do livro se estendesse aos leitores matriculados nas escolas municipais do território, o poder público municipal criou, anexa à Biblioteca Pública, uma secção denominada Biblioteca Circulante, isso por Decreto no 27 de 15 de março de 1954. Ela tinha a finalidade de selecionar e promover o empréstimo de livros aos leitores que nela se inscrevessem previamente. Era intuito difundir entre aos alunos das escolas o interesse pelo conhecimento e o 
hábito de leitura, e que tais práticas favorecessem o campo escolar e as apropriações para o processo de escolarização.

$\mathrm{Na}$ Biblioteca Municipal também aconteciam atividades educativas e culturais do município como recitais de arte e conferências. Pela evolução das circunstâncias histórico educativas, o espaço da biblioteca vinha ocorrer como um suplemento pedagógico e cultural da população. Segundo Magalhães (2004), fazse por este tipo de espaço a inclusão de novos públicos e novas necessidades gerados pelos ideais do governo central, e, assim, o que o autor chama de 'município corporativo' realiza a articulação dos serviços prestados à população e promove inúmeras ações para envolver os indivíduos locais.

Em 1956, a Biblioteca Pública de Londrina organizou a I Maratona Artística e Intelectual, contou com a participação de alunos dos diversos educandários do município, conferindo vários prêmios aos que mais se destacaram. Os prêmios eram oferecidos por particulares. O fato é que eram variados os eventos promovidos por este espaço de cultura.

Nas festas do $22^{\circ}$ aniversário do Município, promoveu a Biblioteca o I Salão de Arte Fotográfica, a que compareceram com trabalhos fotográficos amadores e profissionais de vários pontos do país. Foram expostas 436 fotografias sobre assuntos ou temas diversos. A exposição foi visitada por mais de 8 mil pessoas (LONDRINA, 1956, v. 3).

Além de ser espaço formal de leitura e de promover ocasiões de convívio cultural e de fomentar tais ações entre os sujeitos, a ideia de fomentar cultura aos indivíduos passava pelo espaço da biblioteca evidenciando a validação do ideário pedagógico que transbordava os muros escolares rumo às formas socioculturais em sociedade. Os acontecimentos promovidos pelo espaço da biblioteca, possibilitavam aos frequentadores o convívio com diferentes hábitos e experiências profissionais ligados à cultura e que envolviam o cidadão local e traziam novas reflexões e interferências culturais em diálogo com experiências externas ao município.

Promovida pela Biblioteca Pública Municipal, realizou-se entre os dias 20 e 28 de junho a I Semana do Livro em Londrina, com que se procurou fazer eco local de certame semelhante ao efetuado no Rio de Janeiro e em outras Capitais. 
Constantes palestras radiofônicas, sessões solenes e reuniões, todas alusivas ao livro, além de uma exposição central instalada na rua Maranhão n053, a I Semana do Livro em Londrina, contou com a colaboração de livrarias locais e editoras do País.

Na mesma oportunidade, funcionou na praça Willie Davids a 'Feira do Livro', também de iniciativa da Biblioteca Municipal.

Durante o certame, foram doados à biblioteca assinaturas de revistas e numerosos livros, dentre eles: Cultura moderna, fábulas de La Fontaine, Cultura Histórica do Brasil, Sherlok Holmes, Um Estadista da República, A Lei do Triunfo, memórias de um médico, Summa-Artes e outros (LONDRINA, 1957, v. 4, n.p)

Na ocasião da I Feira do Livro, compareceram representantes de 26 bibliotecas, de 9 editoras nacionais expondo suas obras e teve participação de aproximadamente 3.550 pessoas, conforme o relatório do executivo de 1957 (LONDRINA, 1957, v. 4). A relação escola, cidade, economia e cultura também passa pelo espaço do livro e da leitura. Frequentar a Biblioteca Pública promovia a inclusão do indivíduo que se tornou alfabetizado e ao mesmo tempo segregava aquele que por algum motivo não conseguiu incluir-se ao mundo das letras e palavras. Essa realidade traz a cidade para pensar sua cultura, fomenta uma outra forma de economia e possibilidade de mercado para o público intelectualizado, porém, num mesmo território, também alimenta a diferença social entre os mundos sociais.

O interesse das ações da Biblioteca era também promover a leitura no meio rural por meio de a biblioteca circulante e estas ações continuaram acontecendo no decorrer da década de 1950, assim como as campanhas, exposições e eventos. Pode-se listar alguns acontecimentos voltados ao fomento da educação cultural dos indivíduos: II Semana do Livro(1958); Exposição Central de Livros (1958); campanha efetuada para aquisição de fundos para o $6^{\circ}$ Acampamento Regional de Escoteiros do Paraná (1958); exposição fotográfica concorrendo no 1 Salão Nacional e no III Internacional de Fotografias (1958); II Salão de Arte Fotográfica (1959); III Semana do Livro (1959); I Exposição Filatélica (1959); IV Semana da Criança (1959) que constou uma maratona intelectual promovida entre os alunos dos cursos primários de Londrina.

A leitura e o conhecimento por meio de livros alcançavam cada vez mais leitores e para eles era disponibilizado material selecionado e escolhido por agentes administrativos vinculados à municipalidade. Mesmo sem 'mão de obra' especializada, o poder local organizava as demandas oriundas dos planos de 
governo garantindo o funcionamento e alcance dos recursos didáticos envolvidos na oferta da leitura ao povo. As demandas chegavam aos locais municipais e organizados pela administração municipal.

O ano de 1959 foi comemorado em Londrina devido ao Jubileu de Prata do município. Pelo poder executivo foi instituída uma Comissão Especial afim de realizar solenidades e festividades. A Comissão foi composta por órgãos deliberativo e executivo formados por autoridades, presidentes de entidades de classes, desportivas e recreativas, diretores de estabelecimentos de ensino, entre outros. A Maratona Intelectual foi uma das atividades promovidas e ela ocorreu durante a IV Semana da Criança, realizada pela Biblioteca.

No espaço da Biblioteca Municipal, as experiências sociais e suas expressões culturais envolviam as escolas e escolares. De certa forma, eram incorporadas ao sistema de ensino escolar um lugar de pessoas, de aprendizagem, de seleção e inserção sociocultural. A intenção de trazer cultura ao povo londrinense estava presente nas atividades da Biblioteca. O esforço de Londrina tornar-se cada vez mais um lugar civilizado, dando condições de conhecimento aos indivíduos, também dar-se-ia ao município um status de um lugar favorável ao crescimento do indivíduo, da economia e da vida social. Esse intento se fazia presente nos discursos políticos registrados nas deliberações dos poderes executivo e legislativo.

\section{Considerações Finais}

A construção do município de Londrina (1934-1960), segundo as atas da Câmara Municipal e os relatórios da Prefeitura, contou com ações dos poderes legislativo e executivo destinadas à educação e à cultura. A concepção de município foi se estruturando também a partir de figurações educativas e culturais produzidas pelos indivíduos reveladores do quadro político e da capacidade humana de se educarem em interdependência com o processo de estruturação e ordenamento de uma localidade.

O ordenamento da localidade exigia ações da municipalidade de Londrina mais enfáticas no campo da educação e da cultura para regular comportamentos e modos de ser dos indivíduos em sociedade. Entretanto, a criação e o fomento de 
poucos estabelecimentos escolares eram ações do corpo executivo promovidas em tempos de centralização de poder em plena era Varguista. Enquanto isso, o legislativo, quando existente em razão do estado intervencionista que fechou câmaras legislativas de 1937 a 1945, pouco se discutia, propunha e aprova demandas referentes à escolarização formal. De fato, a educação escolar concorria com outras pautas públicas, entre elas a de saneamento, energia elétrica, pavimentação das ruas, saúde, transporte, trabalho. Por outro lado, as pautas públicas de cultura vão se fazer presentes no debate e nas ações da municipalidade de Londrina, com um pouco mais de força, nas décadas de 1940 e 1950.

A cultura, neste artigo, discutida principalmente com a criação e o funcionamento da Biblioteca Pública de Londrina, representou aos indivíduos na localidade possibilidades de práticas educativas para além dos muros da escola. $\mathrm{A}$ Biblioteca foi uma tática cultural e educacional em resposta às demandas de formação do homem para o mundo da vida social, escolar, das artes, do trabalho, da cidade. O espaço formal de leitura associava-se ao plano de empreender uma concepção de município potente no esforço civilizatório.

As ações culturais e educacionais se entrecruzavam e se validavam no plano regulamentador dos espaços do município em construção. Essa dinâmica se deu pela mobilização dos indivíduos políticos, administrativos, civis e promotores de cultura ocupantes de lugares de poder e que se educavam a partir dos lugares ocupados, seja pelo ambiente das práticas oficiais dos órgãos legislativos/executivos, assim como pelo ambiente formal da escola e fora da escola. Como desfecho, as práticas culturais e educativas devem ser consideradas como centrais na formação do ethos dos londrinenses e da construção do município de Londrina.

\section{Referências}

ADÃO, Áurea; MAGALHÃES, Justino (org.). História dos municípios na educação e na cultura: incertezas de ontem, desafios de hoje. Lisboa: FCT: Universidade de Lisboa, 2011.

ARIAS NETO, José Miguel. O Eldorado: representações da política em Londrina, 1930/1975. 2. ed. Londrina: EDUEL, 2008. 
BONI, Paulo Cesár. Fincando estacas: a história de Londrina (década de 30) em textos e imagens. Londrina: Ed. do autor, 2004.

BRASIL. Constituição da República dos Estados Unidos do Brasil. Rio de Janeiro: Assembleia Nacional Constituinte, 1934.

BRASIL. Constituição da República dos Estados Unidos do Brasil. Rio de Janeiro: Presidência da República, 1937.

BRASIL. Constituição da República dos Estados Unidos do Brasil. Rio de Janeiro: Presidência da República, 1946.

BRASIL. Decreto-Lei n. 1.202, de 8 de abril de 1939. Dispõe sobre a administração dos Estados e dos Municípios. Rio de Janeiro: Presidência da República, 1939.

BRASIL. Decreto-Lei n. 2.416, de 17 de julho de 1940. Aprova a codificação das normas financeiras para os Estados e Municípios. Rio de Janeiro: Presidência da República, 1940.

CAPELO, Maria Regina Clivati. Educação, escola e diversidade no meio rural. Londrina: EDUEL, 2013.

CESÁRIO, Ana Cleide Chiarotti; ALMEIDA, Ana Maria Chiarotti. Imagens da cidade: memória coletiva em Londrina. Mediações, Londrina, v. 1, n. 2, jul./dez.1996.

COUTINHO, Humberto Puiggari. Londrina, 25 anos de sua história. São Paulo: Universal, 1959.

CURY, Carlos Roberto Jamil. Legislação educacional brasileira. Rio de Janeiro: DP\&A, 2002.

ELIAS, Norbert. O processo civilizador: uma história dos costumes. Rio de Janeiro: Jorge Zahar, 1994.

FARIA FILHO, Luciano Mendes; VEIGA, Cynthia Greive. Belo Horizonte: a escola e os processos educativos no movimento da cidade. Varia história, n. 18, p. 203 222. set. 1997.

FARIA FILHO, Luciano Mendes. A legislação escolar como fonte para a história da educação: uma tentativa de interpretação. In: DUARTE, Regina Horta; FARIA FILHO, Luciano Mendes (org.). Educação, modernidade e civilização: fontes e perspectivas de análises para a história da educação oitocentista. Belo Horizonte: Autêntica, 1998. p. 89-125.

FORQUIN, Jean Claude. Escola e cultura: as bases sociais e epistemológicas do conhecimento escolar. Porto Alegre: Artes Médicas, 1993. 
GONÇALVES NETO, Wenceslau; CARVALHO, Carlos Henrique (org.). Ação municipal e educação na Primeira República do Brasil. Belo Horizonte: Mazza Edições, 2015.

LONDRINA. Secretaria de Governo. Decretos municipais. 1942-1945, v.3.

LONDRINA. Câmara Municipal. Livro de Atas, Londrina: CML, 1936, v.1.

LONDRINA. Câmara Municipal. Livro de Atas, Londrina: CML, 1949, v.2.A.

LONDRINA. Câmara Municipal. Livro de Atas, Londrina: CML, 1950, v.3.

LONDRINA. Câmara Municipal. Livro de Atas, Londrina: CML, 1954, v.10

LONDRINA. Câmara Municipal. Livro de Atas, Londrina: CML, 1955-1956, v.14.

LONDRINA. Câmara Municipal. Livro de Leis. Londrina: CML, 1936 a 1937.

LONDRINA. Câmara Municipal. Livro de Leis. Londrina: CML, 1948. v.1.

LONDRINA. Câmara Municipal. Livro de Leis. Londrina: CML, 1950-1951. v.5.

LONDRINA. Câmara Municipal. Livro de Leis. Londrina: CML, 1950-1953. v.9.

LONDRINA. Câmara Municipal. Livro de Relatórios do Executivo. Londrina: CML, 1952-1954. v.2.

LONDRINA. Câmara Municipal. Livro de Relatórios do Executivo. Londrina: CML, 1956. v.3.

LONDRINA. Câmara Municipal. Livro de Relatórios do Executivo. Londrina: CML, 1957. v.4.

LONDRINA. Câmara Municipal. Livro de Relatórios do Executivo. Londrina: CML, 1958. V.5. LONDRINA. Guia geral de Londrina: indicador histórico e comercial. [S. I.]: Empresa Propagandista do Norte do Paraná, 1954. Publicação anual.

LONDRINA. Inventário e proteção do acervo cultural de Londrina: IPAC/LDA: os caminhos do vafé no Paraná: Heimtal, o passado e o presente no vale dos Alemães. Londrina: GRAFMAN, 1993. (Série Estudos, n. 2).

MAGALHÃES, Justino Pereira de. Tecendo nexos: história das instituições educativas. Bragança Paulista: Editora Universitária São Francisco, 2004.

MAGALHÃES, Justino Pereira de. O local e a decisão política em educação: aspectos teóricos e metodológicos da história do município pedagógico. In: COLUBHE - CONGRESSO LUSO-BRASILEIRO DE HISTÓRIA DA EDUCAÇÃO, $7 .$, 2008, Porto. Anais [...]. Porto: [s. n.], 2008. 
PAIVA, Marília de Abreu Martins. Bibliotecas públicas: políticas do estado brasileiro de 1990 a 2006. 2008. Dissertação (Mestrado em Ciência da Informação) - Universidade Federal de Minas Gerais, Belo Horizonte, 2008.

PARANÁ. Lei n. 64, de 21 de fevereiro de 1948. Lei orgânica dos municípios. Curitiba: Palácio do Governo, 1948.

PARANÁ. Decreto Estadual no 2.519 de 03 de dezembro de 1934. Curitiba: Palácio do Governo, 1934.

VEIGA, Cynthia Greive. Cidadania e educação na trama da cidade: a construção de Belo Horizonte em fins do século XIX. 1994. 499 f. Tese (Doutorado em História) - Instituto de Filosofia e Ciências Humanas, Universidade Estadual de Campinas, Campinas, 1994. 